\title{
Cardiology in Brazilian scientific journals: an overview
}

\author{
Cardiologia em revistas científicas brasileiras: um panorama
}

Kavita Kirankumar Patel ${ }^{1}$, Mauricio Rocha e Silva ${ }^{2}$

\begin{abstract}
Cardiology has been and is a very significant fraction of the Brazilian contribution to science. In older days, the most significant part of this work was directed to foreign periodicals, but the quasi-simultaneous emergence of SciELO and PUBMED has ordained a redirection of much of this work to Brazilian periodicals. We here survey some of this more recent contribution for the benefit of readers of Revista Brasileira de Cirurgia Cardiovascular. This is offered as an update. Articles on the general themes of Cardiology and Pneumology published by four ISI Indexed Brazilian journals not specializing in cardiology are re-visited, after a search through 10 journals.
\end{abstract}

\section{INTRODUCTION}

Medical scientific Brazilian journals are going through a phase of improved quality and visibility. This is the result of the rise in Brazilian scientific production and to fifteen years of the beneficial influence of SciELO, the Scientific Electronic Library Online and of the introduction of totally open access to the file of the National Library of Medicine brought about by PUBMED. The increase in the number of ISI-THOMSON indexed journals must also be regarded as a contributing factor. This is a review of papers recently published in non-cardiologic journals on the theme of

1. Editorial Director of the Scientific Journal CLINICS, Faculdade de Medicina and Hospital das Clínicas, Universidade de São Paulo, SP, Brazil

2. Editor-in-Chief of the Scientific Journal CLINICS, Faculdade de Medicina and Hospital das Clínicas, Universidade de São Paulo, SP, Brazil

\begin{abstract}
Resumo
A Cardiologia foi, e continua sendo, responsável por uma fracção muito significativa da contribuição brasileira para a ciência. No passado, os trabalhos mais importantes eram direcionados para periódicos estrangeiros, mas o surgimento quase simultâneo do SciELO e PUBMED facilitou um redirecionamento de grande parte desses trabalhos a periódicos brasileiros. Neste artigo, examinamos algumas das contribuições mais recentes em benefício aos leitores da Revista Brasileira de Cirurgia Cardiovascular. Esta discussão é oferecida como uma atualização. Artigos sobre os temas gerais da cardiologia e pneumologia publicados por quatro revistas brasileiras indexadas no ISI - não especializadas em cardiologia - são revistos.
\end{abstract}

cardio-pneumology. These articles appeared in the Brazilian Journal of Medical and Biological Research, Clinics, Revista da Escola de Enfermagem da USP, and Revista Latinoamericana de Enfermagem. They were selected according to the concept of continuously variable rating: articles are selected through citations vis-à-vis papers in the same journal [1]. As might be expected the majority of selected papers cover cardiac surgery.

\section{General Review}

Surgery contributed 24 articles to this evaluation, where the theme of coronary artery bypass grafting is, not

Correspondence address:

Kavita Kirankumar Patel.

Rua Dr. Ovídio Pires de Campos, $225-6^{\text {th }}$ floor

São Paulo, SP, Brazil - Zip code 05403-010

E-mail: kavita.patel@hc.fm.usp.br 
surprisingly, the most frequent entry. Caputti et al. [2] compared 217 nonrandomized, consecutive, and nonselected patients with left ventricular ejection fractions of less than $20 \%$ who underwent coronary artery bypass graft, with or without cardiopulmonary bypass. They found that in selected patients with severe left ventricular dysfunction the procedure is valid and safe and promotes less mortality and morbidity, compared with conventional operations. Schachner et al. [3] endeavored to determine the influence of preoperative serum $\mathrm{N}$-terminal fragment of pro-brain type natriuretic peptide (an established biomarker for cardiac failure) on postoperative outcome and mid-term survival in 819 patients undergoing isolated coronary artery bypass grafting. They concluded that preoperative peptide levels $>502 \mathrm{ng} / \mathrm{ml}$ predict mid-term mortality after isolated coronary artery bypass grafting and are associated with significantly higher hospital mortality and perioperative complications. Reddy et al. [4] analyzed the sympathetic innervation of the internal thoracic artery to assess the effect of aging on this artery by histomorphometry using 54 human internal thoracic artery samples collected from 27 cadavers (19 male and 8 female) with ages of 19 to 83 years. Sympathetic nerve fibers are present in the adventitia of the internal thoracic artery. This is an elastic artery, although anatomically it is considered to be medium-sized. The sympathetic index may be used for analysis of sympathetic nerve fiber-related problems of the internal thoracic artery and may thus be used to gage the effects of aging thereupon. Nerbass et al. [5] evaluated whether massage therapy is an effective technique for improving sleep quality in patients following cardiopulmonary artery bypass graft surgery and conclude that it is an effective technique for improving patient recovery because it reduces fatigue and improves sleep. Hovnanian et al. [6] endeavored to determine long-term survival, identify preoperative factors predictive of a favorable outcome, and assess functional improvement after coronary artery bypass grafting in 244 patients with advanced left ventricular dysfunction. They claim that in selected patients with severe ischemic left ventricular dysfunction, the level of predominance of tissue viability, may be a tool capable of implementing preoperative clinical/functional parameters in predicting outcome as left ventricular ejection fraction and gated left ventricular ejection fraction at exercise/rest. Lima et al. [7] evaluated the influence of the Nursing Consultation Protocol in aspects of anxiety and depression in 78 patients after myocardial revascularization using the Hospital Anxiety and Depression scale (HAD), providing a sample of 39 patients in the control group (CG) and 39 in the intervention group (IG). It was found that people monitored in accordance with the Nursing Consultation Protocol had a lower percentage of anxiety and depression after six months.

General cardiac surgical themes contribute 5 papers:
Armaganijan et al. [8] conducted a metanalytical survey of randomized trials of $\mathrm{N}-3$ polyunsaturated fatty acid use for postoperative atrial fibrillation using the PUBMED CENTRAL, PUBMED, EMBASE, and LILACS databases. Four randomized studies (three double-blind, one openlabel) that enrolled 538 patients were identified. The patients were predominantly male, the mean age was 62.3 years, and most of the patients exhibited a normal left atrial size and ejection fraction. N-3 polyunsaturated fatty acid use was not associated with a reduction in postoperative atrial fibrillation. Similar results were observed when the openlabel study was excluded. They conclude that there is insufficient evidence to suggest that treatment with $\mathrm{N}-3$ polyunsaturated fatty acids reduces postoperative atrial fibrillation. Therefore, their routine use in patients undergoing cardiac surgery is not recommended. Carneiro et al. [9] performed an exploratory, descriptive cohort study to verify the incidence of patients submitted to cardiac surgery who developed skin lesions during the intraoperative period, and to characterize these lesions. The total incidence was $21 \%$. They observed that $19.2 \%$ of lesions were Pressure Ulcers (PU) in stage I; $1.1 \%$ of lesions were abrasive; $1.1 \%$ incisive; $0.5 \%$ lacerative; $0.5 \%$ superficial electrical burns; and $0.5 \%$ PU in stage II. Miranda et al. [10] analyzed the changes in vital signs of postoperative cardiac surgery patients, according to the referred pain intensity, through a descriptive-exploratory study performed in 38 patients submitted to a first dressing change. The analysis of the data, measured before and after performing the nursing procedure, indicated that the manifestation of pain occurred at different levels. The main changes in vital signs referred to blood pressure. In conclusion, there is a relationship between pain intensity and vital signs, and the care that is delivered is indispensible to reestablishing the health state of the postoperative patient. Torrati et al. [11] aimed to measure the sense of coherence and evaluate its association to sociodemographic variables and the use of psychotropic drugs among 127 patients in the preoperative period of cardiac surgeries. Their results suggest that female and young patients need more attention from nurses in the planning of their perioperative care. Hsu et al. [12] sought to study the associations of ambient noise with heart rate, blood pressure, and perceived psychological and physiological responses among 40 post-cardiac surgery patients in ICUs. The average noise level was between 59.0 and $60.8 \mathrm{~dB}(\mathrm{~A})$ at the study site. Annoyance and insomnia were the respective psychological and physiological responses reported most often among the patients. Although noise level, irrespective of measures, was not observed to be significantly associated with the selfassessed psychological and physiological responses, it was significantly associated with both heart rate and blood 
pressure. They conclude that the noise in ICUs may adversely affect the heart rate and blood pressure of patients, which warrants the attention of hospital administrators and health care workers.

Three other themes appeared important: Tedde et al. [13] compared bar displacement and complication rates in three retrospective series of patients for pectus excavatum operated on by the same surgical team. In the first series, the original, unmodified Nuss technique was performed, in the second, the "third point fixation" technique was used, and in the last series, the correction was performed with modifications to the stabilizer and stabilizer position and found that elimination of fixation wires, the use of shorter bars and redesigned stabilizers placed in a more medial position results in a better outcome for pectus excavatum patients treated with the Nuss technique. Because bar displacement and instability are no longer significant postoperative risks, the Nuss technique should be considered among the available options for the surgical correction of pectus excavatum in pediatric patients. Yuan et al. [14] endeavored to elucidate the relationship between bicuspid aortic valve and aortic dilation A total of 241 bicuspid aortic valve patients were included in this study. In addition to the clinical characteristics of the included patients, the morphological features of the aortic valve and aorta, the length of the left main coronary artery, and the laboratory findings (the coagulation and hematological parameters as well as the total cholesterol concentration) were determined and compared with those of the tricuspid aortic valve patients. Bicuspid aortic valve patients developed aortic wall and aortic valve disorders at a younger age and were predominantly male. Aortic dilation was observed in the aortic root, sinotubular junction, and ascending aortic segments, in both the bicuspid and tricuspid aortic valve patients, although the bicuspid patients had a smaller degree of dilation, which was also significantly age-related in this group. Statin therapy did not affect the aortic annulus in either group, but did decrease the dimensions of the aortic root, sinotubular junction and ascending aorta. In general, statin therapy had a better effect on the aortas of the tricuspid than it did on those of the bicuspid patients. Abreu Filho et al. [15] evaluated the influence of the alloy and the profile of coronary stents on late loss and re-stenosis rates 6 months after implantation in 187 patients with multi-vessel coronary disease. At least one cobalt-chromium and one stainless steel stent were implanted per patient. They conclude that the use of two different alloys, stainless steel and cobaltchrome stents, in the same patient and in the same vessel produced similar 6-month re-stenosis and late loss rates.

Three articles on Transplants were selected: Cinque \& Bianchi [16] endeavored to identify the stressors experienced by family members during the process of organ donation, evince the most distressful moment of the process and verify the association of variable with the family members' experience. The sample consisted of 16 family members that were making the donation through an Organ Search Organization, in São Paulo, in 2007. They found that the donation process is sufficiently stressful on the family to make nursing care necessary in each stage of the process to offer support and reduce the distress on the family members. Guimarães et al. [17] evaluated the neurohormonal activity in heart transplant recipients and compared it with that in heart failure patients and healthy subjects during rest and just after a 6-minute walking test. During rest, norepinephrine was higher in heart transplant recipients and healthy subjects. Immediately after the 6minute walking test, the heart transplant and heart failure patients had higher norepinephrine levels than healthy subjects. Thus neurohormonal activity remains increased after the 6-minute walking test in heart transplantation recipients. Martino et al. [18] endeavored to determine if bone marrow mononuclear cell transplantation is safe for moderate to severe idiopathic dilated cardiomyopathy. Twenty four patients (age $46 \pm 11.6$ years, 17 males) with idiopathic dilated cardiomyopathy, with optimized therapy, NYHA classes II-IV, and left ventricular ejection fraction $<35 \%$ were enrolled in the study. Clinical evaluation was performed at baseline and 6 months after stem cell therapy to assess heart function. They claim that their findings indicate that the transplantation therapy in these patients with severe ventricular dysfunction is feasible and that larger, randomized and placebo-controlled trials are warranted.

Four articles on vascular surgery have been selected, Serrano et al. [19] endeavored to identify the functional results after aneurysm surgery in patients with ischemic cardiomyopathy and to determine predictors of favorable outcomes in 169 patients with angiographic left ventricular ejection fraction of $22 \pm 5 \%$, who underwent aneurysm surgery, and were prospectively followed for three years. Prior to surgery, $40 \%$ and $60 \%$ of the patients were in congestive heart failure NYHA class I/II and III/IV, respectively. Concomitant revascularization was performed on $95 \%$ of the patients and suggest that aneurysmectomy among patients with severe LV dysfunction result in short and long-term favorable functional outcome and survival. Selection of appropriate surgical candidates may substantially improve survival rates among these patients. Sincos et al. [20] retrospectively analyzed and compared the results of conventional surgical repair and endovascular treatment of blunt aortic injury in 26 patients treated for blunt aortic injury. Twenty-six patients were included in the study, 5 treated with operative repair and 21 with endovascular treatment and found that endovascular treatment was a safe method for repair of blunt aortic trauma, 
with immediate and midterm results that were comparable to those results obtained with operative repair. No complications from the stent graft were identified during follow-up. Nevertheless, long-term follow-up is necessary to confirm the effectiveness of this treatment. Morales et al. [21] performed a duplex ultrasound study to investigate morphological and hemodynamic patterns of carotid stenoses treated by endarterectomy with patch closure versus stenting in 29 carotid stenoses treated with stenting and 65 with patch closure. Measurements over time in luminal diameter signalized differences in arterial remodeling mechanisms between patched and stented carotids. Both stenting and patch closure were associated with carotid patency and flow restoration. This study does not support a general approach to new velocity criteria indiscriminately applied to stented or patched carotids. Orlando et al. [22] analyzed the results of treating deep venous malformations patients with low doses of ethanol in 39 patients treated between 1995 and 2007, followed up prospectively over a median period of 18 months. They conclude that outpatient treatment for deep venous malformations using ethanol at low doses was effective, with a low complication rate.

An article on Lung surgery was frequently cited: TerraFilho et al. [23] evaluated the clinical and hemodynamic characteristics of 35 chronic thromboembolic pulmonary hypertension patients scheduled for pulmonary thromboendarterectomy in a referral center for chronic thromboembolic pulmonary hypertension treatment. They concluded that chronic thromboembolic pulmonary hypertension patients evaluated for pulmonary thromboendarterectomy had a hemodynamically severe status and elevated brain natriuretic peptide serum levels.

On the theme of Hyperhydrosis, Wolosker et al. [24] assessed the quality of life of 1044 patients submitted to video-assisted thoracic sympathectomy for treating palmar hyperhydrosis according to gender and conclude that patients with palmar hyperhydrosis present an improvement in the quality of life after video-assisted thoracic sympathectomy regardless of gender.

Dias et al. [25] examined the severity of trauma in 1203 motor vehicle accident entrapped vs. non-entrapped victims to identify risk factors for mortality and morbidity. Entrapped victims were predominantly men $(84.8 \%)$, aged $32 \pm 13.1$ years, with immediate mortality of $10.2 \%$ and overall mortality of $11.7 \%$. They had a probability of death at the scene 8.2 times greater than that of non-entrapped victims. The main cause of death was hemorrhage for entrapped victims and trauma for non-entrapped victims. Thus entrapped victims had greater trauma severity, more blood loss, and a greater mortality than respective, non-entrapped controls.

Clinical cardiology, pneumology and renal/cardiological articles contributed 22 entries, with the interaction of exercise with heart function as the most frequent. Casonatto et al. [26] investigated in ten male subjects the effects of aerobic exercise with a cycle ergometer on the acute blood pressure response and to evaluate the indicators of autonomic activity after exercise. Authors did not find a reduction in blood pressure after exercise in normotensive, physically active young adults. However, the measurements of the indicators of autonomic neural activity revealed that in exercise of greater intensity the parasympathetic recovery tends to be slower and that sympathetic withdrawal can apparently compensate for this delay in recovery. Ciolac and Greve [27] compared the heart rate response to exercise and the exercise-induced improvements in muscle strength, cardiorespiratory fitness and heart rate response between normal-weight and overweight/obese postmenopausal women and conclude that overweight/obese women displayed impaired heart rate response to exercise. Both groups improved muscle strength, but only normal-weight women improved cardiorespiratory fitness and heart rate response to exercise. These results suggest that exerciseinduced improvements in cardiorespiratory fitness and heart rate response to exercise may be impaired in overweight/obese postmenopausal women. Farinatti et al. [28] evaluated heart rate, systolic blood pressure and ratepressure product of 22 asymptomatic volunteers during and after large and small muscle group flexibility exercises performed simultaneously with the Valsalva maneuver. They found that both the stretched muscle mass and the VM influence acute cardiovascular responses to multiple-set passive stretching exercise sessions. Galvão et al. [29] employed a murine model to investigate the effect of opioid receptor blockade on the myocardial protection conferred by chronic exercise and to compare exercise training with different strategies of myocardial protection (opioid infusion and brief periods of ischemia-reperfusion) preceding irreversible left anterior descending coronary ligation. They found that exercise training, morphine, exercise training plus morphine, and ischemia-reperfusion groups had a smaller infarct area than the control group. The effect of chronic exercise training in decreasing infarct size seems to occur, at least in part, through the opioid receptor stimulus, and not by increasing myocardial perfusion. Machado et al. [30] investigated the behavior of heart rate and heart rate variability during different loads of resistance exercise (incline bench press) in ten patients with coronary artery disease vs. ten healthy sedentary controls and conclude that loads up to $30 \%$ one-repetitionmaximum during incline bench press, result in depressed vagal modulation in both groups, although only the coronary artery disease patients presented sympathetic overactivity at $20 \%$ one-repetition-maximum upper limb exercise. Kanegusuku et al. [31] determined in 30 older adults whether different resistance training regimens, 
strength training (constant movement velocity) or power training (concentric phase performed as fast as possible) can blunt the increase in cardiovascular load during an aerobic stimulus and conclude that neither strength nor power training blunted submaximal or maximal heart rate, Systolic blood pressure or the rate-pressure product during the maximal exercise test, showing that they did not reduce cardiovascular stress during aerobic tasks. Mainenti et al. [32] investigated the effects of levothyroxine on cardiopulmonary exercise reserve and recovery in 23 women with subclinical hypothyroidism submitted to two ergospirometry tests, with an interval of 6 months of normalization of thyroid-stimulating hormone levels (levothyroxine replacement group) or simple observation. No relevant differences were observed in cardiopulmonary recovery for either group at baseline or after follow-up. In the sample studied, levothyroxine replacement improved exercise cardiopulmonary reserve, but no modification was found in recovery performance after exercise during this period of analysis. Martins-Pinge [33] focused on some groups of neurons involved in sympathetic regulation, including the nucleus tractus solitarii, caudal ventrolateral medulla and the rostral ventrolateral medulla that maintain and regulate the cardiac and vascular autonomic tonus. The results of these studies suggest that the beneficial effects of physical activity may be due, at least in part, to reductions in sympathetic nervous system activity. Conversely, with the recent association of physical inactivity with chronic disease, these data may also suggest that increases in sympathetic nervous system activity contribute to the increased incidence of cardiovascular diseases associated with a sedentary lifestyle. Oliveira et al. [34], in view of the fact that exercise oxygen pulse (O pulse), a surrogate for stroke volume and arteriovenous oxygen difference, has emerged as an important variable obtained during cardiopulmonary exercise testing hypothesized that the $\mathrm{O}$ pulse curve pattern response to a maximal cycling ramp protocol exhibits a stable linear pattern in subjects reevaluated under the same clinical conditions. Their findings show that, excluding the rest-exercise transition, the relative $\mathrm{O}$ pulse exhibited a stable linear increase throughout maximal exercise in adults that were retested under same clinical conditions. Peres et al. [35] analyzed the acute effect of submaximal exercise on aortic distensibility using pulse wave velocity and other hemodynamic variables in patients with Marfan Syndrome with either mild or no aortic dilatation. Pulse wave velocity and physiological variables were evaluated before and after submaximal exercise in 33 patients with Marfan Syndrome and in 18 healthy controls. Using comparative group analysis regarding PWV at rest and at the end of exercise they conclude that no statistically significant differences occurred. The same was true for the group that used beta- blockers and the one that did not. The final heart rate and final systolic arterial pressure were higher in the control group vs. the Marfan Syndrome group, whereas pulse wave velocity did not differ between groups after submaximal effort. Perim el al. [36] analyzed the stability of the $\mathrm{O}_{2}$ pulse curve relative to body mass in elite athletes. $\mathrm{VO}_{2}$, heart rate (HR), and relative $\mathrm{O}_{2}$ pulse were compared at every $10 \%$ of the running time in two maximal cardiopulmonary exercise tests, repeated within a one-year interval, in 49 soccer players. They conclude that in young healthy men in good to excellent aerobic condition, the morphology of the relative $\mathrm{O}_{2}$ pulse curve is consistent up to close to the peak effort for a cardiopulmonary exercise testing repeated within a 1-year period. They also claim that no increase in relative $\mathrm{O}_{2}$ pulse at peak effort could represent a physiologic stroke volume limitation in these athletes.

Diagnosis is the second most frequent entry. Gimenes et al. [37] determined the response characteristics and functional correlates of the dynamic relationship between the rate $(\ddot{\mathrm{A}})$ of oxygen consumption $\left(\mathrm{VO}_{2}\right)$ and the applied power output (work rate $=$ WR) during ramp-incremental exercise in 14 patients with mitochondrial myopathy vs. 10 sedentary controls. They claim that a readily available, effort-independent index of aerobic dysfunction during dynamic exercise is typically reduced in patients with mitochondrial myopathy, being related to increased functional impairment and higher cardiopulmonary stress. Martins et al. [38] investigated high-sensitivity C-reactive protein levels as predictors of acute myocardial infarction risk in 101patients undergoing high-risk noncardiac surgery and found that such patients especially vascular surgery patients presenting elevated baseline high-sensitivity Creactive protein levels are at increased risk for perioperative acute myocardial infarction. Myers et al. [39] examined the association between cardiac performance during recovery and the severity of heart failure, as determined by clinical and cardiopulmonary exercise test responses. They find that impaired cardiac output recovery kinetics can identify heart failure patients with more severe disease, lower exercise capacity, and inefficient ventilation. Estimating cardiac output in recovery from exercise may provide added insight into the cardiovascular status of patients with heart failure. They conclude that in this heterogeneous study population, stress cardiomyopathy presented with a $3: 2$ female-to-male ratio, and dyspnea was the most common chief complaint. Stress cardiomyopathy exhibited a T wave inversion as the primary EKG abnormality. These findings differ from previously reported data, and the authors conclude that further studies are needed. Rosoky et al. [40] investigated whether oxidized low-density lipoprotein is a suitable predictor of peripheral arterial disease severity in 85 consecutive patients with an ankle-brachial pressure index $(\mathrm{ABPI})<0.9$ and the presence of either intermittent 
claudication or critical lower leg ischemia and conclude that oxidized low-density lipoprotein is not a good predictor of peripheral arterial disease severity. Simsek et al. [41] evaluated $\mathrm{P}$ wave dispersion in patients with iron deficiency anemia and the possible relationships between $P$ wave dispersion and other echocardiographic parameters in 97 patients who had iron deficiency anemia and 50 healthy subjects. They conclude that iron deficiency anemia may be associated with prolonged $\mathrm{P}$ wave duration and dispersion and impaired diastolic left ventricular filling. Yuksel et al. [42] aimed to retrospectively investigate the relationship between admission levels of serum yglutamyltransferase and poor myocardial perfusion after primary percutaneous coronary intervention in patients with acute myocardial infarction in 80 patients with thrombolysis in myocardial infarction grades $0 / 1$ flow preprocedurally. The patients were divided into two groups according to thrombolysis in myocardial perfusion grades that were assessed immediately following primary percutaneous coronary intervention. The two groups (group 1 and group 2) each consisted of 40 patients with thrombolysis in myocardial perfusion grades $0-1$ and thrombolysis in myocardial perfusion grades 2-3, respectively and found that high admission ãglutamyltransferase levels are associated with poor myocardial perfusion in patients with acute myocardial infarction undergoing primary percutaneous coronary intervention, particularly in patients with prolonged pain to balloon time.

Two papers cover Hypertension: de Souza Nery et al. [43] describe blood pressure responses during resistance exercise in ten hypertensive vs. ten normotensive subjects to determine whether an exercise protocol alters these responses and found that resistance exercise increased systolic blood pressure considerably more in hypertensives than in normotensives, and this increase was greater when lower-intensity exercise was performed to the point of exhaustion. Medeiros et al. [44] investigated the hemodynamic responses to mental stress before and after a bout of exercise in subjects with prehypertension and found that such patients exhibited elevated blood pressure and a blunted vasodilator response during mental stress, but their blood pressure was attenuated and their vasodilator response was normalized after a single bout of maximal dynamic exercise.

The theme of Heart failure is introduced by Correale et al. [45] who retrospectively analyzed 353 consecutive outpatients with chronic heart failure (mean follow-up 384 days), based on whether or not statin therapy was used. In all patients, several Tissue Doppler Imaging parameters were measured; circulating levels of interleukin IL-6, IL-10 and C-reactive protein were also assayed. They conclude that chronic ischemic heart failure outpatients undergoing statin treatment had fewer readmissions for adverse events, blunted inflammatory activation, and improved left ventricular performance assessed by Tissue Doppler Imaging.

Two articles cover the Renal/Cardiological interaction: Duran et al. [46] analyzed the effect of maintenance hemodialysis on left ventricular diastolic function in 42 patients with end-stage renal disease and found that disease treatment in these patients with hemodialysis via arteriovenous fistulae induce a variety of hemodynamic and metabolic abnormalities that predispose to alterations in left and right ventricular functions. They claim that left ventricular diastolic function and right ventricular functions were not significantly changed, but that left ventricular systolic functions were impaired after maintenance hemodialysis treatment in these patients. Girardi et al. [47] assessed the effects of rosuvastatin on renal injury and inflammation in a murine model of nitric oxide deficiency and found that rosuvastatin treatment reduced glomerular damage due to improvement in the inflammatory pattern independent of the systolic blood pressure and serum lipid level. These effects may lead to improvements in the treatment of kidney disease.

The basic science themes of Pathology, Physiology and Molecular Biology are covered in 9 articles, 6 cardiac, 2 pulmonary, and one renal: Carneiro-Júnior et al. [48] determined the effects of exercise training and detraining on the morphological and mechanical properties of left ventricular myocytes in 4-month-old spontaneously hypertensive rats (SHR) randomly divided into sedentary for 8 weeks, sedentary for 12 weeks, treadmill-running trained for 8 weeks (TRA, $16 \mathrm{~m} / \mathrm{min}, 60 \mathrm{~min} /$ day, 5 days/ week), and treadmill-running trained for 8 weeks followed by 4 weeks of detraining. Cell length was greater in TRA than in SED-8 and remained larger after detraining. Cell width and volume were unaffected by either exercise training or detraining. Exercise training did not affect cell shortening, which was unchanged with detraining. TRA cells exhibited higher maximum velocity of shortening than SED-8 with almost complete regression after detraining. They conclude that exercise training affected left ventricle remodeling in SHR towards eccentric hypertrophy, which remained after detraining. It also improved single left ventricular myocyte contractile function, which was reversed by detraining. Piratello et al. [49] evaluated the role of angiotensin I, II and 1-7 on left ventricular hypertrophy of Wistar and spontaneously hypertensive rats submitted to sinoaortic denervation and conclude that not only blood pressure variability and reduced baroreflex sensitivity but also elevated levels of angiotensin II and a reduced concentration of angiotensin 1-7 may contribute to the development of left ventricular hypertrophy. These data indicate that baroreflex dysfunction associated with 
changes in the renin angiotensin system may be predictive factors of left ventricular hypertrophy and cardiac failure. Roque et al. [50] investigated the effects of swimming training on coronary blood flow, adenosine production and cardiac capillaries in normotensive rats and found that swimming training increases coronary blood flow, number of cardiac capillaries, and adenine nucleotide hydrolysis. Increased adenosine production may be an important contributor to the enhanced coronary blood flow and angiogenesis that were observed in the exercise-trained rats; collectively, these results suggest improved myocardial perfusion. Soares et al. [51] examined the effect of exercise training without or with a $3 \%$ workload on different cardiac and renal parameters in renovascular hypertensive (2K1C) male Fisher rats weighing 150-200 g. Morphometric evaluation showed concentric left ventricle hypertrophy in sedentary rats. Unloaded exercise prevented concentric cardiac hypertrophy, increased cardiomyocyte diameter and decreased cardiac vasculature thickness. In contrast, 3\% loaded exercise reduced concentric remodeling and prevented the increase in cardiac vasculature wall thickness, decreased the cardiomyocyte diameter and increased collagen deposition. Renal morphometric analysis showed that Ex $3 \%$ induced an increase in vasculature wall thickness and collagen deposition in the left kidney of $2 \mathrm{~K} 1 \mathrm{C}$ rats. These data suggest that unloaded exercise has more beneficial effects than the loaded modality. Valenti et al. [52] compared baroreflex sensitivity among a subset of normotensive Wistar Kyoto rats which show lower baroreflex sensitivity and found that approximately $37 \%$ of the rats showed a reduced bradycardic peak, bradycardic reflex and decreased bradycardic gain of baroreflex while roughly $23 \%$ had a decreased basal HR, tachycardic peak, tachycardic reflex and reduced sympathetic baroreflex gain. No significant alterations were noted with regard to basal MAP. They conclude that there is variability regarding baroreflex sensitivity among Wistar Kyoto rats from the same laboratory. Veiga et al. [53] investigated whether previous exercise training could prevent or attenuate acute cardiac alterations after myocardial infarction in female rats submitted to swim training or allowed to remain sedentary for 8 weeks. They were randomly assigned to left coronary artery occlusion or sham surgery and found that previous swim training does not attenuate systolic and diastolic function alterations after myocardial infarction induced by left coronary artery occlusion, suggesting that cardioprotection cannot be provided by exercise training in this experimental model. Capelozzi et al. [54] performed a histopathological analysis of the open lung biopsy specimens from five patients with ARDS with confirmed $\mathrm{H} 1 \mathrm{~N} 1$ and claim that viral-like particles can be successfully demonstrated in lung tissue by ultrastructural examination, without confirmation of the virus by RT-PCR on nasopharyngeal aspirates. Bronchioles and epithelium, rather than endothelium, are probably the primary target of infection, and diffuse alveolar damage the consequence of the effect of airways obliteration and dysfunction on innate immunity, suggesting that treatment should be focused on epithelial repair. Valenti et al. [55] evaluated the effects of central catalase inhibition on cardiopulmonary reflex in conscious Wistar rats and concluded that increased sympathetic inhibition does not change the parasympathetic component of the cardiopulmonary reflex in these conscious animals. Garcia-Pinto et al. [56] endeavored to observe the beneficial effects of lowintensity physical activity on structural and ultrastructural renal morphology and blood pressure in normotensive and spontaneously hypertensive rats. They found that exercised, spontaneously hypertensive rats showed a significant blood pressure reduction of $26 \%$. The body masses of the Wistar-Kyoto and spontaneously hypertensive strains were significantly different. There were improvements in some of the renal structures of the animals treated with physical activity. The spontaneously hypertensive rats also showed a decreased expression of connexin-43. They conclude that physical exercise could be a therapeutic tool for improving kidney ultrastructure and, consequently, renal function in hypertensive individuals.

Anesthesiology for thoracic surgery contributes 3 original research themes: Basagan-Mogol et al. [57] evaluated the hemodynamic and analgesic effects of ketamine by prospectively comparing it with propofol starting at the induction of anesthesia until the end of sternotomy in 30 patients undergoing coronary artery bypass grafting surgery. There were no differences between groups in the consumption of sevoflurane or in the use of additional fentanyl. The combination of ketamine, midazolam, and fentanyl for the induction of anesthesia provided better hemodynamic stability during induction and until the end of sternotomy in patients undergoing coronary artery bypass grafting surgery. Hajjar et al. [58] evaluated whether arterial lactate or standard base deficit on admission and after 24 hours can predict mortality for patients with cancer. They evaluated 1,129 patients with severe sepsis, septic shock, or postoperative after highrisk surgery. Lactate and standard base deficit collected at admission and after 24 hours were compared between survivors and non-survivors. Their findings suggest that lactate and standard base deficit measurement should be included in the routine assessment of patients with cancer admitted to the intensive care unit with sepsis, septic shock or after high-risk surgery. These markers may be useful in the adequate allocation of resources in this population. Ornek et al. [59] investigated the effects of sevoflurane general anesthesia vs. bupivacaine selective spinal 
anesthesia on electrocardiographic QT dispersion and corrected QT interval though a prospective, randomized, double-blind study conducted on 40 patients undergoing noncardiac surgery randomized into two groups. They conclude that although Volatile Induction and Maintenance of Anesthesia with sevoflurane might prolong the QT corrected interval with no resulting arrhythmia, selective spinal anesthesia with bupivacaine was not associated with alterations in the QT interval or arrhythmia.

\section{REFERENCES}

1 Rocha e Silva M. Continuously variable rating: a new, simple and logical procedure to evaluate original scientific publications. Clinics (Sao Paulo). 2011;66(12):2099-104.

2. Caputti GM, Palma JH, Gaia DF, Buffolo E. Off-pump coronary artery bypass surgery in selected patients is superior to the conventional approach for patients with severely depressed left ventricular function. Clinics (Sao Paulo). 2011;66(12):2049-53.

3. Schachner T, Wiedemann D, Fetz H, Laufer G, Kocher A, Bonaros N. Influence of preoperative serum N-terminal probrain type natriuretic peptide on the postoperative outcome and survival rates of coronary artery bypass patients. Clinics (Sao Paulo). 2010;65(12):1239-45.

4. Reddy S, Kumar P, Prasad K. Histomorphometric and sympathetic innervation of the human internal thoracic artery. Clinics (Sao Paulo). 2011;66(1):131-6.

5. Nerbass FB, Feltrim MI, Souza SA, Ykeda DS, Lorenzi-Filho G. Effects of massage therapy on sleep quality after coronary artery bypass graft surgery. Clinics (Sao Paulo). 2010;65(11):1105-10.

6. Hovnanian AL, Matos Soeiro A, Serrano CV, Oliveira SA, Jatene FB, Stolf NA, et al. Surgical myocardial revascularization of patients with ischemic cardiomyopathy and severe left ventricular disfunction. Clinics (Sao Paulo). 2010;65(1):3-8.

7. Lima FE, De Araújo TL, Serafim EC, Custódio IL. Nursing consultation protocol for patients after myocardial revascularization: influence on anxiety and depression. Rev Lat Am Enfermagem. 2010;18(3):331-8.

8. Armaganijan L, Lopes RD, Healey JS, Piccini JP, Nair GM, Morillo CA. Do omega-3 fatty acids prevent atrial fibrillation after open heart surgery? A meta-analysis of randomized controlled trials. Clinics (Sao Paulo). 2011;66(11):1923-8.

9. Carneiro GA, Leite RC. Skin lesions in the intraoperative period of cardiac surgery: incidence and characterization. Rev Esc Enferm USP. 2011;45(3):611-6.
10. Miranda AF, da Silva LF, Caetano JA, de Sousa AC, Almeida PC. [Evaluation of pain intensity and vital signs in the cardiac surgery postoperative period]. Rev Esc Enferm USP. 2011;45(2):327-33.

11. Torrati FG, Gois CF, Dantas RA. [Strategy in the care of cardiac surgical patients: evaluation of the sense of coherence]. Rev Esc Enferm USP. 2010;44(3):739-44.

12. Hsu SM, Ko WJ, Liao WC, Huang SJ, Chen RJ, Li CY, et al. Associations of exposure to noise with physiological and psychological outcomes among post-cardiac surgery patients in ICUs. Clinics (Sao Paulo). 2010;65(10):985-9.

13. Tedde ML, Campos JR, Das-Neves-Pereira JC, Abrao FC, Jatene FB. The search for stability: bar displacement in three series of pectus excavatum patients treated with the Nuss technique. Clinics (Sao Paulo). 2011;66(10):1743-6.

14. Yuan SM, Jing H, Lavee J. The bicuspid aortic valve and its relation to aortic dilation. Clinics (Sao Paulo). 2010;65(5):497-505.

15. Abreu Filho LM, Forte AA, Sumita MK, Favarato D, Meireles GC. Influence of metal alloy and the profile of coronary stents in patients with multivessel coronary disease. Clinics (Sao Paulo). 2011;66(6):985-9.

16. Cinque VM, Bianchi ER. Stressor experienced by family members in the process of organ and tissue donation for transplant. Rev Esc Enferm USP. 2010;44(4):996-1002.

17. Guimarães GV, D'Avila V, Bocchi EA, Carvalho VO. Norepinephrine remains increased in the six-minute walking test after heart transplantation. Clinics (Sao Paulo). 2010;65(6):587-91.

18. Martino HF, Oliveira PS, Souza FC, Costa PC, Assunção e Silva E, Villela R, et al. A safety and feasibility study of cell therapy in dilated cardiomyopathy. Braz J Med Biol Res. 2010;43(10):989-95.

19. Serrano CV Jr, Ramires JA, Soeiro AM, César LA, Hueb WA, Dallan LA, et al. Efficacy of aneurysmectomy in patients with severe left ventricular dysfunction: favorable short-and longterm results in ischemic cardiomyopathy. Clinics (Sao Paulo). 2010;65(10):947-52.

20. Sincos IR, Aun R, Belczak SQ, Nascimento LD, Mioto Netto B, Casella I, et al. Endovascular and open repair for blunt aortic injury, treated in one clinical institution in Brazil: a case series. Clinics (Sao Paulo). 2011;66(2):267-74.

21. Morales MM, Anacleto A, Buchdid MA, Simeoni PR, Ledesma S, Cêntola C, et al. Morphological and hemodynamic patterns of carotid stenosis treated by endarterectomy with patch closure versus stenting: a duplex ultrasound study. Clinics (Sao Paulo). 2010;65(12):1315-23. 
22. Orlando JL, Caldas JG, Campos HG, Nishinari K, Wolosker $\mathrm{N}$. Outpatient percutaneous treatment of deep venous malformations using pure ethanol at low doses under local anesthesia. Clinics (Sao Paulo). 2010;65(9):837-40.

23. Terra-Filho M, Mello MF, Lapa MS, Teixeira RH, Jatene FB. Clinical and haemodynamic evaluation of chronic thromboembolic pulmonary hypertension patients scheduled for pulmonary thromboendarterectomy: Is schistosomiasis hypertension an important confounding factor? Clinics (Sao Paulo). 2010;65(11):1155-60.

24. Wolosker N, Munia MA, Kauffman P, Campos JR, Yazbek G, Puech-Leão P. Is gender a predictive factor for satisfaction among patients undergoing sympathectomy to treat palmar hyperhidrosis? Clinics (Sao Paulo). 2010;65(6):583-6.

25. Dias AR, Abib SC, Poli-de-Figueiredo LF, Perfeito JA. Entrapped victims in motor vehicle collisions: characteristics and prehospital care in the city of São Paulo, Brazil. Clinics (Sao Paulo). 2011;66(1):21-5.

26. Casonatto J, Tinucci T, Dourado AC, Polito M. Cardiovascular and autonomic responses after exercise sessions with different intensities and durations. Clinics (Sao Paulo). 2011;66(3):453-8.

27. Ciolac EG, Greve JM. Exercise-induced improvements in cardiorespiratory fitness and heart rate response to exercise are impaired in overweight/obese postmenopausal women. Clinics (Sao Paulo). 2011;66(4):583-9.

28. Farinatti PT, Soares PP, Monteiro WD, Duarte AF, Castro LA. Cardiovascular responses to passive static flexibility exercises are influenced by the stretched muscle mass and the Valsalva maneuver. Clinics (Sao Paulo). 2011;66(3):459-64.

29. Galvão TF, Matos KC, Brum PC, Negrão CE, Luz PL, Chagas AC. Cardioprotection conferred by exercise training is blunted by blockade of the opioid system. Clinics (Sao Paulo). 2011;66(1):151-7.

30. Machado HG, Simões RP, Mendes RG, Castello V, Di Thommazo L, Almeida LB, et al. Cardiac autonomic modulation during progressive upper limb exercise by patients with coronary artery disease. Braz J Med Biol Res. 2011;44(12):1276-84.

31. Kanegusuku H, Queiroz AC, Chehuen MR, Costa LA, Wallerstein LF, Mello MT, et al. Strength and power training did not modify cardiovascular responses to aerobic exercise in elderly subjects. Braz J Med Biol Res. 2011;44(9):864-70.

32. Mainenti MR, Teixeira PF, Oliveira FP, Vaisman M. Effect of hormone replacement on exercise cardiopulmonary reserve and recovery performance in subclinical hypothyroidism. Braz $\mathbf{J}$ Med Biol Res. 2010; 43(11):1095-101.

33. Martins-Pinge MC. Cardiovascular and autonomic modulation by the central nervous system after aerobic exercise training. Braz J Med Biol Res. 2011;44(9):848-54.
34. Oliveira RB, Myers J, Araújo CG. Long-term stability of the oxygen pulse curve during maximal exercise. Clinics (Sao Paulo). 2011;66(2):203-9.

35. Peres P, Bernardelli GF, Mendes CC, Fischer SS, Servantes DM, Medeiros WM, et al. Immediate effects of submaximal effort on pulse wave velocity in patients with Marfan syndrome. Braz J Med Biol Res. 2010;43(4):397-402.

36. Perim RR, Signorelli GR, Araújo CG. Stability of relative oxygen pulse curve during repeated maximal cardiopulmonary testing in professional soccer players. Braz J Med Biol Res. 2011;44(7):700-6.

37. Gimenes AC, Neder JA, Dal Corso S, Nogueira CR, Nápolis L, Mello MT, et al. Relationship between work rate and oxygen uptake in mitochondrial myopathy during ramp-incremental exercise. Braz J Med Biol Res. 2011;44(4):354-60.

38. Martins OM, Fonseca VF, Borges I, Martins V, Portal VL, Pellanda LC. C-Reactive protein predicts acute myocardial infarction during high-risk noncardiac and vascular surgery. Clinics (Sao Paulo). 2011;66(5):773-6.

39. Myers JN, Gujja P, Neelagaru S, Hsu L, Burkhoff D. Noninvasive measurement of cardiac performance in recovery from exercise in heart failure patients. Clinics (Sao Paulo). 2011;66(4):649-56.

40. Rosoky RM, Wolosker N, Nasser M, Zerati AE, Gidlund M, Puech-Leão P. Oxidized low-density lipoprotein and ankle-brachial pressure index in patients with clinically evident peripheral arterial disease. Clinics (Sao Paulo). 2010;65(4):383-7.

41. Simsek H, Gunes Y, Demir C, Sahin M, Gumrukcuoglu HA, Tuncer M. The effects of iron deficiency anemia on $\mathrm{p}$ wave duration and dispersion. Clinics (Sao Paulo). 2010;65(11):1067-71.

42. Yuksel UC, Celik T, Celik M, Bugan B, Iyisoy A, Yaman H. High admission levels of ?-glutamyltransferase predict poor myocardial perfusion after primary percutaneous intervention. Clinics (Sao Paulo). 2011;66(10):1729-34.

43. de Souza Nery S, Gomides RS, da Silva GV, de Moraes Forjaz CL, Mion D Jr, Tinucci T. Intra-arterial blood pressure response in hypertensive subjects during low- and high-intensity resistance exercise. Clinics (Sao Paulo). 2010;65(3):271-7.

44. Medeiros RF, Silva BM, Neves FJ, Rocha NG, Sales AR, Nobrega AC. Impaired hemodynamic response to mental stress in subjects with prehypertension is improved after a single bout of maximal dynamic exercise. Clinics (Sao Paulo). 2011;66(9):1523-9.

45. Correale M, Brunetti ND, Totaro A, Montrone D, Russo AR, Fanigliulo AM, et al. Statin therapy blunts inflammatory activation and improves prognosis and left ventricular performance assessed by Tissue Doppler Imaging in subjects 
with chronic ischemic heart failure: results from the Daunia Heart Failure Registry. Clinics (Sao Paulo). 2011;66(5):777-84.

46. Duran M, Unal A, Inanc MT, Esin F, Yilmaz Y, Ornek E. Effect of maintenance hemodialysis on diastolic left ventricular function in end-stage renal disease. Clinics (Sao Paulo). 2010;65(10):979-84.

47. Girardi JM, Farias RE, Ferreira AP, Raposo NR. Rosuvastatin prevents proteinuria and renal inflammation in nitric oxidedeficient rats. Clinics (Sao Paulo). 2011;66(8):1457-62.

48. Carneiro-Júnior MA, Pelúzio MC, Silva $\mathrm{CH}$, Amorim PR, Silva KA, Souza MO, et al. Exercise training and detraining modify the morphological and mechanical properties of single cardiac myocytes obtained from spontaneously hypertensive rats. Braz J Med Biol Res. 2010;43(11):1042-6.

49. Piratello AC, Moraes-Silva I, Paulini J, Souza PR, Sirvente R, Salemi V, et al. Renin angiotensin system and cardiac hypertrophy after sinoaortic denervation in rats. Clinics (Sao Paulo). 2010;65(12):1345-50.

50. Roque FR, Soci UP, De Angelis K, Coelho MA, Furstenau $\mathrm{CR}$, Vassallo DV, et al. Moderate exercise training promotes adaptations in coronary blood flow and adenosine production in normotensive rats. Clinics (Sao Paulo). 2011;66(12):2105-11.

51. Soares ER, Lima WG, Machado RP, Carneiro CM, Silva ME, Rodrigues $\mathrm{MC}$, et al. Cardiac and renal effects induced by different exercise workloads in renovascular hypertensive rats. Braz J Med Biol Res. 2011;44(6):573-82.

52. Valenti VE, de Abreu LC, Imaizumi C, Petenusso M, Ferreira C. Strain differences in baroceptor reflex in adult Wistar Kyoto rats. Clinics (Sao Paulo). 2010;65(2):203-8.
53. Veiga EC, Antonio EL, Bocalini DS, Murad N, Abreu LC, Tucci PJ, et al. Prior exercise training does not prevent acute cardiac alterations after myocardial infarction in female rats. Clinics (Sao Paulo). 2011;66(5):889-93.

54. Capelozzi VL, Parra ER, Ximenes M, Bammann RH, Barbas CS, Duarte MI. Pathological and ultrastructural analysis of surgical lung biopsies in patients with swine-origin influenza type A/H1N1 and acute respiratory failure. Clinics (Sao Paulo). 2010;65(12):1229-37.

55. Valenti VE, Abreu LC, Sato MA, Ferreira C. ATZ (3-amino1,2,4-triazole) injected into the fourth cerebral ventricle influences the Bezold-Jarisch reflex in conscious rats. Clinics (Sao Paulo). 2010;65(12):1339-43.

56. Garcia-Pinto AB, de Matos VS, Rocha V, Moraes-Teixeira J, Carvalho JJ. Low-Intensity physical activity beneficially alters the ultrastructural renal morphology of spontaneously hypertensive rats. Clinics (Sao Paulo). 2011;66(5):855-63.

57. Basagan-Mogol E, Goren S, Korfali G, Turker G, Kaya FN. Induction of anesthesia in coronary artery bypass graft surgery: the hemodynamic and analgesic effects of ketamine. Clinics (Sao Paulo). 2010;65(2):133-8.

58. Hajjar LA, Nakamura RE, de Almeida JP, Fukushima JT, Hoff PM, Vincent JL, et al. Lactate and base deficit are predictors of mortality in critically ill patients with cancer. Clinics (Sao Paulo). 2011;66(12):2037-42.

59. Ornek E, Ornek D, Alkent ZP, Ekin A, Basaran M, Dikmen $B$. The effects of volatile induction and maintenance of anesthesia and selective spinal anesthesia on QT interval, QT dispersion, and arrhythmia incidence. Clinics (Sao Paulo). 2010;65(8):763-7. 